Public Health

\section{Raw milk and the protection of public health}

$\mathrm{T}$ he raw-food movement, characterized by eating raw rather than cooked food, is a fledgling but growing trend in North America. One product that might be incorporated and distributed under this movement is raw, or unpasteurized, milk. Physicians, members of the public and public health officials need to be alert to the fact that raw milk is a hazardous product.

Raw milk is a known vehicle and medium for pathogens such as $E s$ cherichia coli, Mycobacterium bovis, Listeria monocytogenes and species of Campylobacter, Brucella and Salmonella. ${ }^{1}$ From 1988 to 2005 , a total of 33 outbreaks of campylobacter, salmonella and E. coli Or57: $\mathrm{H}_{7}$ infections associated with raw-milk consumption were reported to the US Centers for Disease Control and Prevention. ${ }^{2}$ The most recently reported outbreak involved 18 cases with a mean age of 9 years. Of the cases, 4 were admitted to hospital with hemolytic uremic syndrome. In England and Wales, from 1992 to 2000, I4 outbreaks of infectious intestinal diseases that were associated with rawmilk consumption were reported to the UK Communicable Disease Surveillance Centre. ${ }^{3}$ In Canada, there were 4 reported cases in 2005 of illness due to $E$. coli $\mathrm{O}_{157}: \mathrm{H}_{7}$ infections that were associated with raw-milk consumption in Ontario. ${ }^{4}$

Milk can become contaminated in many ways. For example, if a dairy cow has a mammary gland infection (mastitis) or a systemic infection, the pathogen can be passed to the milk. Milk can also become contaminated by manure dust or by equipment used for milk collection or storage. A number of hygienic practices, such as vigilant and routine equipment cleaning and attention to proper storage and handling of milk, can reduce the risk of contamination. Pasteurization, which in Ontario involves heating and maintaining the temperature of the milk to $72^{\circ} \mathrm{C}$ for 16 seconds, greatly reduces the bacterial load in collected milk. Provided that the Health hazard

Food premises

\section{Operator}

pasteurized milk is adequately stored and refrigerated and is consumed before the established "best-before" date, the risk of infection from consuming pasteurized milk is very low.

In developed countries, most jurisdictions have enacted legislation to ensure the safety of milk products. In Canada, the sale of raw milk has been strictly prohibited since I99I under the federal Food and Drug Regulations. These regulations require that all milk for sale in Canada be pasteurized. Provinces may pass laws with respect to the prohibition of unpasteurized milk within their sphere of jurisdiction, provided that their laws do not conflict with federal legislation.

The move to require milk pasteurization in Ontario was spearheaded in the I89os by Adelaide Hoodless, following the death of her young son after he acquired an infection from raw milk. Through her efforts, the Women's Institute was founded, which later influenced the introduction of milk pasteurization in the I930s in the Public Health Act. In 1965 , the Milk Act came into force. The Milk Act regulates the quality of milk products sold in Ontario and requires that all distributors and operators of premises where milk products are processed be licensed (Box I). The Ontario Ministry of Agriculture and Food and Rural Affairs (OMAFRA) is responsible for enforcement of the
Milk Act. Currently, the investigations and prosecutions of OMAFRA are carried out by the investigative arm of the Ontario Ministry of Natural Resources.

In 1983 , the Health Protection and Promotion Act $^{5}$ came into force and replaced the Public Health Act. The act sets out a mandate for boards of health with respect to the provision of public health services, and it sets out the powers and duties of the chief medical officer and the medical officers of health in Ontario, among other things. Several sections of the act provide investigative and enforcement powers that enable medical officers of health and their delegates to investigate and prevent the distribution of raw milk and raw-milk products. An exception to the Health Protection and Promotion Act was created by the Ontario Food Premises Regulations for cheese made from unpasteurized milk. The sale of this product is not prohibited if it has been stored below $2^{\circ} \mathrm{C}$ for at least 60 days following manufacturing.

The following hypothetical case illustrates how the public health system of Ontario would respond to a case of raw-milk exposure.

\section{The case}

A medical officer of health receives 2 laboratory-confirmed reports of $E$. coli. When the health unit staff investigate, they learn that the cases shared the same exposure, namely, consumption of raw milk distributed at a local corner store. The public health inspector visits

Box 1: Glossary of terms included in the Health Protection and Promotion Act

- A condition of a premises,

- A substance, thing, plant or animal other than man, or

- A solid, liquid, gas or combination of any of them,

that has or that is likely to have an adverse effect on the health of any person.

- A premises where food or milk is manufactured, processed, prepared, stored, handled, displayed, distributed, transported, sold or offered for sale, but does not include a private residence.

- In relation to a food premises, a person who has responsibility for and control over an activity there carried on, although there is more than one operator of the same food premises. 
the store to inspect the milk; however, the store owner forbids entry.

\section{What action can be taken?}

Section Io of the Health Protection and Promotion Act requires that medical officers of health inspect food premises. In this case, by forbidding entry, the store owner is obstructing the medical officer of health, according to section 42 of the act. Under section 43 of the act, the medical officer of health can secure a warrant to enter the premises.

\section{How is a warrant secured?}

A medical officer of health or public health inspector may secure a warrant from a justice of the peace. The person seeking the warrant must demonstrate that it is necessary to gain entry and access the premises and to carry out examinations, investigations, tests and inquiries. The evidentiary material accompanying the warrant application should demonstrate the medical officer's right to inspect, the reason for the inspection and that entry has been denied.

\section{What precautions must be taken when executing a warrant?}

The need to apply for a warrant signals the potential for resistance and physical violence; thus, the police must be alerted to the scenario and need for a warrant. Police assistance should be sought when it is necessary to enter a premises using a warrant, because health unit staff are not trained to handle violence. The public health laboratory should be alerted about forthcoming samples.

\section{What is seized?}

Under section I9 of the act, all hazardous material may be seized to protect the public. Samples should immediately be transported to the public health laboratory. Evidence of the enzyme phosphatase in the milk indicates that it has not been adequately pasteurized. The samples should also be tested for evidence of pathogenic contamination.

\section{What happens if the samples test positive?}

If the laboratory reports evidence of raw milk or unacceptable pathogenic contamination, the medical officer of health or public health inspector can issue a "cease-and-desist" order under section I3 of the act forbidding further distribution of unpasteurized milk products. If the operator contravenes the order by refusing to cease distribution, the medical officer of health can charge the operator under section roo of the act. The operator can be fined up to $\$ 5000$ for each day or part day that the order is violated.

\section{How can the operator appeal an order?}

There is a stepwise progression of appeals available to the operator. The first step is to appeal the order to the Ontario Health Services Appeal and Review Board. The board's decision can be appealed to the Ontario Divisional Court. The next appeal lies with the Court of Appeal for Ontario, with permission of the court. In Ontario, the sale of unpasteurized milk has only been considered once by the Health Services Appeal and Review Board. In 1994, the board determined that there were reasonable and probable grounds to conclude that the unpasteurized milk and milk products produced by the appellant, except for cheese aged for 60 days or longer, constituted a health hazard (Box I).

\section{How can further contravention of an order be prevented?}

The medical officer can make an application under section I02 of the act to the Ontario Superior Court of Justice. The judge may order any action deemed necessary to prevent the person from contravening the order. If the operator fails to comply with the court order, it is possible to seek a contempt order from the Superior Court.

\section{Conclusion}

The Health Protection and Promotion Act pertains to the jurisdictional boundaries of the health unit. Occa- sionally, hazardous products may be distributed across the boundaries of several health units. In this scenario, the units must cooperate and coordinate efforts to provide consistent practices and standards. The chief medical officer of health and the Ministry of Health and Long-Term Care can play a coordinating and leadership role. In Ontario, the Ministry of Natural Resources also has a role to play, particularly if there is provincial impact. In cases with the involvement of numerous jurisdictions and ministries, it is essential to define the roles and responsibilities on matters of investigations, communication, enforcement and legal applications.

Increased education and awareness are additional mechanisms available to public health staff to prevent the consumption of raw milk. When a specific source of raw-milk exposure is identified, public health efforts should ensure that residents of the affected area are aware and informed of the risk. Orders and warrants can be issued expeditiously, but investigation and enforcement takes time, and there may be lengthy procedures and delays.

Enforcement has the potential to escalate to violence. Good cooperation and communication between public health staff and local police are essential for enforcement of warrants and orders. These relationships should be established well before the need for enforcement arises.

Sensitivity to public perception and media coverage is also an important consideration. Regulation and enforcement represent the extreme end of the spectrum of prevention and control interventions. Fostering good, trusting relationships with local media and establishing a reasonable voice on matters of risk assessment and communication well before a crisis arises can be invaluable.

Erica Weir MD MSc

Community Health and Epidemiology

Queen's University

Kingston, Ont.

Regional Municipality of York

Joanne Mitchell BA LLB

Regional Municipality of York

Steven Reballato MASc

Health Protection

Regional Municipality of York 
Dominic Fortuna BASc

Health Protection

Regional Municipality of York, Ont.

The views expressed in this article are those of the authors and not of the Regional Municipality of York.

This article has been peer reviewed.
Competing interests: None declared.

\section{REFERENCES}

I. Leedom JM. Milk of nonhuman origin and infectious diseases in humans. Clin Infect Dis 2006;43: 6ro-5.

2. US Centers for Disease Control and Prevention. Escherichia coli oI $57: \mathrm{H}_{7}$ infection associated with drinking raw milk - Washington and Oregon, November-December 2005. MMWR 2007;56:165-7.
3. Gillespie IA, Adak GK, O'Brian SJ, et al. Milkborne general outbreaks of infectious intestinal disease, England and Wales, I992-2000. Epidemiol Infect 2003;130:461-8.

4. Statement from Health Canada about drinking raw milk. Ottawa: Health Canada; 2007. Available: www.hc-sc.gc.ca/fn-an/securit/facts-faits/rawmilklaitcru_e.html (accessed 2007 Aug 20).

5. Health Protection and Promotion Act. Available: lelaws_statutes_9oho7_e.htm (accessed 2007 Aug 24). www.e-laws.gov.on.ca/html/statutes/english

\section{Health and Drug Alerts}

\section{Diabetes drug pioglitazone (Actos): risk of fracture}

Reason for posting: Pioglitazone is an oral hypoglycemic agent widely used as monotherapy or combination therapy for type 2 diabetes mellitus. However, a recent analysis by the drug's manufacturer of several unpublished clinical trials in the company's database revealed an increased risk of bone fracture among pioglitazone users. Health Canada and the drug's manufacturer recently issued a letter warning health care professionals about this potential serious adverse effect. ${ }^{1}$

The drug: Pioglitazone is a thiazolidinedione (also known as a TZD, or "glitazone"). It binds to and activates peroxisome proliferator-activated receptors (PPAR), including the PPAR gamma and alpha subtypes. These receptors in turn increase glucose utilization and decrease glucose production by the liver, and increase insulin sensitivity in adipose and muscle tissue.

The Health Canada advisory ${ }^{1}$ was based on an unpublished, manufacturer-led review of double-blind randomized controlled trials of pioglitazone use in diabetic patients. Primary outcome measures in the trials included glycemic control, liver function and vascular events. The trials were not designed specifically to assess fracture risk, and fractures were recorded as adverse events. The doses of pioglitazone used are unclear. Participants in the comparison group were given either a placebo or another diabetic drug (metformin or a sulfonylurea).

Nineteen studies were included in the review. The durations varied from I 6 weeks to 3.5 years. No clinically relevant demographic details about the participants were provided (e.g., age,
Table 1: Factors that identify people who should be assessed for osteoporosis

\begin{tabular}{ll}
\hline Major risk factors & \multicolumn{1}{c}{ Minor risk factors } \\
\hline - Age > 65 years & - Rheumatoid arthritis \\
- Vertebral compression fracture & - Past history of clinical \\
- Fragility fracture after age 40 & hyperthyroidism \\
- Family history of osteoporosis fracture & - Long-term anticonvulsant therapy \\
(especially maternal hip fracture) & - Low dietary calcium intake \\
- Systemic glucocorticoid therapy of & - Smoker \\
$>3$ months' duration & - Excessive alcohol intake \\
- Malabsorption syndrome & - Excessive caffeine intake \\
- Primary hyperparathyroidism & - Weight < 57 kg \\
- Propensity to fall & - Weight loss $>10 \%$ of weight at age 25 \\
- Osteopenia apparent on x-ray film & - Chronic heparin therapy \\
- Hypogonadism & \\
- Early menopause (before age 45) & \\
\hline
\end{tabular}

Adapted from CMAJ 2002;167(Suppl 10):1-34. risk factors for osteoporosis), and it is unclear whether the treatment and comparison groups were comparable. In total, 8157 patients received pioglitazone, and 7442 were in the comparison group.

There was no apparent increase in fracture risk among men, but the advisory did not state baseline fracture rates for the treatment or comparison groups. Among women, $2.6 \%$ of those in the pioglitazone group experienced fractures, as compared with only $1.7 \%$ in the comparison group. This translates to a number needed to harm of III patients. The fracture rate was I.9 fractures per roo patient-years in the pioglitazone treated group and I.I fractures per 100 patient-years in the comparison group. In other words, fractures occurred in $\mathrm{I}$ of 52 patients taking pioglitazone for a year, as compared with I of 90 patients taking either a placebo or another diabetes drug.

Most of the fractures occurred in distal upper and lower limbs and, to a lesser degree, in the hip and spine. ${ }^{2}$ The specific proportions involving each skeletal location was not stated in the advisory, nor was the severity or the mechanism of the fracture (i.e., trauma v. osteoporosis-related).

Thiazolidinediones have been found to cause bone loss in some rodent models. In humans, their effects may occur because of increased bone marrow adiposity, decreased osteoblast activity, or reduced aromatase activity leading to altered estrogen production and increased bone resorption. ${ }^{2}$ In a separate prospective observational study, 3075 community-dwelling adults in their 70 s were followed for 4 years; thiazolidinedione use was associated with reduced bone mineral density in women but not in men. ${ }^{2}$

Prospective randomized trials of thi- 